\title{
Application of novel synthesized nanocomposites containing $\kappa$-carrageenan/PVA/eggshell in cement mortars
}

\author{
I. Sanrı-Karapınar ${ }^{\mathrm{a}} \bowtie$, A. O. Pehlivan ${ }^{\mathrm{a}}$, S. Karakuş ${ }^{\mathrm{b}}$, A. E. Özsoy-Özbay ${ }^{\mathrm{a}}$, \\ A. U. Yazgan ${ }^{\mathrm{a}}$, N. Taşaltın ${ }^{\mathrm{c}}$, A. Kilislioğlu ${ }^{\mathrm{b}}$ \\ a. Department of Civil Engineering, Faculty of Engineering and Natural Sciences, Maltepe University (Istanbul, Turkey) \\ b. Department of Chemistry, Istanbul University-Cerrahpașa, Faculty of Engineering (Istanbul, Turkey) \\ c. Department of Electrical and Electronics Engineering, Faculty of Engineering and Natural Sciences, \\ Maltepe University (Istanbul, Turkey) \\ $\bowtie$ : isilkarapinar@maltepe.edu.tr
}

Received 21 May 2020

Accepted 31 July 2020

Available on line 3 November 2020

\begin{abstract}
This study is a preliminary attempt to present the preparation and the first time a $\kappa$-carrageenan/ PVA/eggshell nanostructure is used as a novel biodegradable and homogeneous nanostructure in cement composition. In order to clearly understand the effects these additives have on the mechanical properties of cementitious composites, they were synthesized in double and triple combinations and added into mortar mixtures. Three different cement mortar specimens were prepared by integrating the additives in ratios of $0,0.1,0.5$ and $1 \%$ by cement weight and flexural and compressive strengths of the specimens were determined at the ages of 7 and 28 days. The flowability of the presented nanostructures was also discussed. The results revealed a $10-11 \%$ increase in both compressive and flexural strengths for the specimens prepared with the triple combination of the proposed additives. Moreover, strain capacity was enhanced as a result of the efficient dispersion of additives in the cement matrix.
\end{abstract}

KEYWORDS: Nanocomposites; Nanoeggshell; $\kappa$-carrageenan; PVA; Cement mortar.

Citation/Citar como: Sanrı-Karapınar, I; Pehlivan, A.O.; Karakuş, S.; Özsoy-Özbay, A.E.; Yazgan, A.U.; Taşaltın, N.; Kilislioğlu, A. (2020) Application of novel synthesized nanocomposites containing א-carrageenan/ PVA/eggshell in cement mortars. Mater. Construcc. 70 [340], e235 https://doi.org/10.3989/mc.2020.06720

RESUMEN: Aplicación en morteros de cemento de nuevos nanocompuestos sintetizados que contienen к-carragenano, PVA y cáscara de huevo. Este estudio es un intento preliminar de introducir la preparación y el uso de $\kappa$-carragenano/PVA/cáscara de huevo como una nueva nanoestructura homogénea y biodegradable en la composición de cemento. Para comprender claramente los efectos de estos aditivos en las propiedades mecánicas de los compuestos cementantes, se sintetizaron combinaciones dobles y triples de éstos, y se agregaron a las mezclas de mortero. Se prepararon tres muestras diferentes de mortero de cemento integrando los aditivos en proporciones de $0,0.1,0.5$ y $1 \%$ en peso del cemento y se determinó la resistencia a flexión y a compresión de las muestras a 7 y 28 días de edad. También se discute la fluidez de las nanoestructuras presentadas. Los resultados revelaron un aumento del $10-11 \%$ en la resistencia a compresión y a flexión de las muestras preparadas con la combinación triple de los aditivos propuestos. Además, la deformabilidad se mejoró como resultado del papel de dispersión eficiente de los aditivos en la matriz de cemento.

PALABRAS CLAVE: Nanocompuestos; Nano-cáscara de huevo; $\kappa$-carragenano; PVA; Morteros de cemento.

ORCID ID: I. Sanr1-Karapınar (https://orcid.org/0000-0002-3695-5867); A.O.. Pehlivan (https://orcid.org/0000-00026296-4126); S. Karakuş (https://orcid.org/0000-0002-8368-4609); A.E. Özsoy-Özbay (https://orcid.org/0000-0001-5397398X); A.U. Yazgan (https://orcid.org/0000-0003-2622-868X); N. Taşaltın (https://orcid.org/0000-0001-6788-1605); A. Kilislioğlu (https://orcid.org/0000-0002-9662-8390)

Copyright: (C) 2020 CSIC. This is an open-access article distributed under the terms of the Creative Commons Attribution 4.0 International (CC BY 4.0) License 


\section{INTRODUCTION}

Recently, the use of natural wastes such as rice husks, sugar canes, wheat straws, corn stalks, groundnut shells, coconut shells and eggshells have been preferred due to their environmentally beneficial and high economic potential in construction applications (1-5). Given the problem of waste disposal and management, researchers have been investigating the suitability of using some of these wastes as a replacement for conventional aggregates in concrete.

Eggshell, a natural biological waste, has an important place among household and food industry wastes. As a low-cost agricultural byproduct that is produced at the rate of several tons per day, eggshell contains high amounts of calcium carbonate, $1 \%$ of magnesium carbonate, $1 \%$ of calcium phosphate, and $4 \%$ of organic material (6-8). Because the calcium compounds in its composition are similar to those in lime, the use of fine eggshell powder for partial replacement of cement or as a filler in cementitious composites can prevent the depletion of natural lime and reduce environmental impacts. The potential use of eggshells has been investigated in an attempt to obtain alternative construction material for the production of ceramic wall tiles (9) and soil bricks (10). It has also been suggested that eggshells in ash be used in road stabilization practice to reduce the setting time of stabilized road pavements (11). Moreover, the calcium oxide found in eggshells has an accelerating effect on hydration and reduces the setting time in cement paste (12). Earlier studies on the addition of eggshell powder in cementitious composites have revealed that partially replacing cement with eggshell powder leads to an increase in compressive strength up to a level of 5\% eggshell substitution by weight of cement (13-17). The reduction in strength that is observed at higher eggshell powder contents is attributed to the dilution of cement within the composition (18).

A detailed review of the literature illustrates that the primary interest is the use of the powder form of eggshells, usually hand-crushed, in the cementitious materials. Moreover, eggshells are good candidates for synthesizing high-performance materials (19-21). Therefore, the synthesized formulation of eggshells in nanoscale can be a promising achievement in concrete technology and construction applications due to its engineering properties (22). It has been reported that the inclusion of nanosized eggshell in cementitious composites can provide a denser cement paste, leading to improved performance for cement-based composite materials. The research presented in this article is based on a previous study by the authors in which a novel hierarchical nanoeggshell was prepared using an eco-friendly technique in order to apply it to construction for the first time (22).
Polyvinyl alcohol (PVA) is a non-ionic, synthetic polymer that is water-soluble, tasteless, colorless, odorless, and anti-toxic. It is one of the main polymers used in different fields of application in construction. The use of PVA in cement-based composite materials has many advantages. Studies in this area of application have focused primarily on improving the cement matrix of mortar and concrete by using PVA (23-27), and research has revealed that adding PVA to ordinary Portland cement leads to a clear improvement in the properties of cementbased composites $(24,28)$. One such advantage is workability, which was found to be enhanced by adding PVA to the cement matrix (23). The literature also contains many examples of PVA's effect on the mechanical properties of cement-based composites. Studies have observed different results for the compressive strength of cement-based composites with added PVA $(23,27)$. Even though one study found that the compressive strength decreased by a moderate amount in the cement mortar with PVA (23), another reported an improvement in strength (27). The reduction in the compressive strength in the former was claimed to be caused by the increase in the number of air voids due to addition of PVA, whereas the improvement in the compressive strength in the latter was attributed to the reduction in porosity due to PVA being used with rice husk ash. Moreover, some studies have pointed out that the flexural strength of the cement with PVA was higher than the unmodified cement (23). In another study, the influence of the curing conditions on the flexural and splitting tensile strengths was also underscored and a dry curing condition for cement mortar with PVA was suggested (29). Also, the water absorption rate was observed to be much slower in cement mortar with PVA (23). Previous studies have examined the durability performance of PVA added cement-based composites with PVA as well (24, $28,30)$. As the pores were filled with PVA, porosity was reduced and an improvement in durability was observed. Due to the lubricating effect of PVA, dispersion becomes easier and the agglomeration of cement particles is avoided. Therefore, pore volumes decrease and a denser microstructure forms.

The use of PVA fibers as reinforcement in cement-based composites is another important application in the field. Taking advantage of their high strength and high modulus of elasticity, highperformance in the production of cementitious composites is feasible (31-33). The studies showed that mechanical properties were attributed to the type of PVA fiber and the amount used in the composites (34-36). The findings of one study indicated the effectiveness of different PVA fibers that have different lengths and volume fractions (37). It was noted that as the volume fraction of PVA fibers in composites increased, there was a reduction in flow $(36,37)$. On the other hand, enhancement in the 
fracture toughness, impact resistance and ductility were observed in fiber-reinforced composites (32). Also, more recent evidence revealed that PVA fibers in cementitious composites including nanosilica improved the microscopic structure and increased the tensile strength significantly (38-40). While the substitution of both nanosilica and calcium carbonate nanoparticles increased the durability of PVA fiber reinforced cementitious composites, they also decreased flowability (40). Further experimental investigations also showed that the mechanical properties like compressive, flexural, and tensile strength and fracture toughness in cementitious composites having PVA fibers and nanosilica changed due to particle size (41).

$\kappa$-carrageenan, a unique cement mixture additive introduced in this study, is a water-soluble biopolymer. It has emulsifying, gelation and thickening properties based on disaccharide units of d-galactose and 3,6-anhydro-d-galactose linked by $\alpha-1,3$ and $\beta-1,4$-glycosidic linkages (42-44). The $\kappa$-carrageenan-based systems are an FDA-approved food additive and have been used in pharmaceutical applications and the food industry (45-48). In the literature, to the best of our knowledge, $\kappa$-carrageenan has not yet been applied in construction applications. One of the first attempts to synthesize and characterize a bio-based superabsorbent copolymer from $\kappa$-carrageenan and polyacrylic acid reported that early age behavior of Portland cement paste can be enhanced as a result of the noted swelling behavior and autogenous shrinkage findings (49).

In this study, a polymer blend of water-soluble, anti-toxic, and biocompatible polyvinyl alcohol (PVA) polymer was prepared with $\mathrm{\kappa}$-carrageenan. $\kappa$-carrageenan/PVA-based nanostructures have been studied in the removal of dyes (50), in controlled drug release systems (51), and in biosensor applications (52) in limited studies. The modified eggshell was added to the polymer mixture using an ultrasound effect to obtain a homogeneous nanostructure. With this simple, green and low-cost method, high-yield nanostructures were obtained at room temperature and at a frequency response of $20 \mathrm{kHz}$. The sonochemical method, which is based on high-energy ultrasonic irradiation, creates a temperature of up to $500^{\circ} \mathrm{C}$ and a pressure of $50 \mathrm{MPa}$ within a few microseconds (53-57). The sonochemical method is preferred in synthesizing nano-sized materials and various colloidal systems $(54,58-62)$.

As stated above, there have been studies on whether the engineering properties of cementbased composites can be improved by additional substances. There is evidence that the properties of cementitious composites can be improved by using the nanoeggshell additive that the current authors proposed in a previous study, and the primary findings have spurred the use of this nanostructure in future research (22). In consideration of the foregoing, reviewing the advantages of using eggshell (a waste material) and PVA in cement-based composites led to the present study's aim of investigating the effect of combining a series of proposed 3D flower-like nanoeggshell, PVA and $\kappa$-carrageenan on the mortar. Given this aim, double and triple combinations of these additives were used in mortar mixtures. Three different cement mortar specimens were prepared by adding nanoeggshells in ratios of $0.1,0.5$, and $1 \%$ by weight, and flexural and compressive strengths of the specimens were determined at the ages of 7 and 28 days.

This study is the first investigation to propose an optimum combination of nanoeggshell, PVA and $\kappa$-carrageenan in cement mortar for mechanical analysis. The result indicate that this novel nanomixture is an environment-friendly, safe and lowcost alternative in construction applications.

\section{MATERIALS AND METHODS}

\subsection{Materials}

Ordinary Portland cement PC $42.5 \mathrm{R}$ with the specific surface of $0.35 \mathrm{~m}^{2} / \mathrm{g}$ and acquired from cement producer Akçansa (Turkey) was used as the binder in this study. River sand $(0-5 \mathrm{~mm})$ was used as fine aggregate. The white eggshells used were obtained from a local farm in Pendik (Istanbul, Turkey). Additionally, $\kappa$-carrageenan, a sulfated plant polysaccharide, was purchased from Sigma Aldrich (Germany) and polyvinyl alcohol (PVA, Mw of $60000 \mathrm{gmol}^{-1}$ ), acetic acid (Glacial, $100 \%$ ) and ethanol were purchased from Merck (Germany). All reagents were of analytical grade.

\subsubsection{Preparation of PVA/Eggshell}

Five grams of PVA were dissolved in $50 \mathrm{ml}$ of deionized water at $80^{\circ} \mathrm{C}$ and the solution was allowed to stand at room temperature for 3 days. 0.1 grams of eggshell were added to $50 \mathrm{ml}$ of $\% 1$ glacial acetic acid solution and sonicated using a probe sonicator for one hour in an ultrasonic homogenizer. PVA and eggshell solutions were sonicated for one hour at 25 $\pm 2^{\circ} \mathrm{C}$ and $35 \%$ amplitude.

\subsubsection{Preparation of $\kappa$-carrageenan/Eggshell}

$\kappa$-carrageenan ( 0.1 grams $)$ was dissolved in 50 $\mathrm{ml}$ of deionized water on a magnetic stirrer at room temperature. Eggshell (0.1 grams) was added to 50 $\mathrm{ml}$ of $\% 1$ glacial acetic acid solution and sonicated using a probe sonicator for one hour in an ultrasonic homogenizer. $\kappa$-carrageenan and eggshell solutions were sonicated for one hour at $25 \pm 2{ }^{\circ} \mathrm{C}$ and $35 \%$ amplitude. 


\subsubsection{Preparation of $\kappa$-carrageenan/PVA/Eggshell}

The white eggshell was cleaned with ultrapure water several times at room temperature and placed in a microwave oven $(720 \mathrm{~W})$ at $25^{\circ} \mathrm{C}$ for $10 \mathrm{~min}$. Then $50 \mathrm{~mL}$ of water/ethanol $(1 / 1, \mathrm{v} / \mathrm{v})$ solution was mixed with the eggshell and the solution was placed in the microwave oven for 5 minutes. Next, the eggshell solution was added to $50 \mathrm{ml}$ of glacial acetic acid/ultrapure water $(1: 49, \mathrm{v} / \mathrm{v})$ solution and sonicated for $1 \mathrm{~h}$ at $35 \%$ amplitude $(25 \mathrm{kHz}$ frequency, $400 \mathrm{~W})$. Five grams of PVA were mixed in $50 \mathrm{ml}$ of water at $80^{\circ} \mathrm{C}$ and kept at room temperature for 5 days in a dark medium. 0.1 grams of $\kappa$-carrageenan were dissolved in $50 \mathrm{ml}$ of water at room temperature. The PVA and $\kappa$-carrageenan were mixed and the eggshell was added to the $\kappa$-carrageenan/PVA blend. The solution was sonicated for $1 \mathrm{~h}$ at $20 \mathrm{kHz}$ (viscosity: $8.12 \mathrm{cP}, \mathrm{pH}$ : 3.8). The $\kappa$-carrageenan/PVA/eggshell nanostructure was filtered through a sterile filter ( 0.22 micron) and stored in a sterile container at $25^{\circ} \mathrm{C}$.

\subsubsection{Characterization}

Scanning electron microscopy (SEM) (FE-SEM, JEOL 63335F) (gold coating, $20 \mathrm{kV}$ accelerating voltage), zetasizer analysis (Malvern Ins. Zetasizer) and Fourier transform infrared spectrometry (FTIR) (PerkinElmer spectrum two FTIR spectrometer; KBr powder, $4000 \mathrm{~cm}^{-1}$ to $500 \mathrm{~cm}^{-1}$ with a resolution of $4 \mathrm{~cm}^{-1}$ using 8 scans) were used to determine morphological properties and chemical functional groups of the nanostructure. The Brunauer-Emmett-Teller (BET) specific surface area of the nanostructure was determined using a Micromeritics ASAP 2020 model.

\subsubsection{Preparation of mortar specimens}

Mortar specimens were cast in steel molds with the dimensions 40 × 40 x $160 \mathrm{~mm}$. All mixtures tested within this study had the same water-cement ratio, and mix proportions were held constant within a standard ratio of cement:sand:water (2:2:1). No admixture was incorporated for workability or any other use. Double and triple combinations of $\kappa$-carrageenan (k), PVA (P) and nanoeggshell (NES) were used in the mortar specimens with different percentages $(0,0.1,0.5,1 \%)$ by cement weight. Table 1 shows the mixture compositions of the combinations. Since the proposed additives were in solution form, water content was adjusted to avoid variations in water-cement ratio. Thus, the amount of solution was decreased from the water content to stabilize the water-cement ratio as 0.5 .

Mixtures were prepared in accordance with the specifications given in TS EN 12390-6 (63) using a Hobart mixer. The dry mixture was made by mixing cement and river sand for 1 minute with no water. A separate water mixture was prepared by adding the triple additive combination $\mathrm{kP}-\mathrm{NES}$ to water and mixing until it was uniformly distributed in the water. The water mixture and dry mixtures were subsequently added together and mixed for 2 minutes. All specimens were demolded after 24 hours under laboratory conditions and transferred to water tanks stabilized at a curing temperature of $20^{\circ} \mathrm{C}$.

\subsubsection{Flowability tests of mortar specimens}

The flowability of the mortar mixtures was tested within the specifications given in ASTM C1437-15 (64). Tests were performed with an Abrams cone, filling it with the mortar mixtures to its full height $(50 \mathrm{~mm})$ in two layers on top of a flow table. After lifting the cone filled with mortar mixture, the flow table was dropped 25 times in 15 seconds, and the diameter of the mortar was measured along two perpendicular directions.

\subsubsection{Mechanical testing of mortar specimens}

Mortar specimens were taken out of the water tanks on the $7^{\text {th }}$ and $28^{\text {th }}$ day and left in ambient laboratory conditions prior to mechanical testing.

TABLE 1. Compositions of mortar mixtures.

\begin{tabular}{|c|c|c|c|c|c|}
\hline & Additive Content (\%) & Cement (g) & Sand (g) & Water (g) & Additive (g) \\
\hline Control & 0 & 1000 & 1000 & 500 & 0 \\
\hline$\kappa \mathrm{P}-\mathrm{NES} 1$ & 0.1 & 1000 & 1000 & 499 & 1 \\
\hline кP-NES5 & 0.5 & 1000 & 1000 & 495 & 5 \\
\hline кP-NES10 & 1 & 1000 & 1000 & 490 & 10 \\
\hline$\kappa-N E S 1$ & 0.1 & 1000 & 1000 & 499 & 1 \\
\hline$\kappa-N E S 5$ & 0.5 & 1000 & 1000 & 495 & 5 \\
\hline$\kappa-\mathrm{NES} 10$ & 1 & 1000 & 1000 & 490 & 10 \\
\hline P-NES1 & 0.1 & 1000 & 1000 & 499 & 1 \\
\hline P-NES5 & 0.5 & 1000 & 1000 & 495 & 5 \\
\hline P-NES10 & 1 & 1000 & 1000 & 490 & 10 \\
\hline
\end{tabular}


Flexural and compressive strength tests were carried out on the same specimens in accordance with TS EN 12390-7 (65). Flexural strength was measured using an MTS closed-loop servo-hydraulic mechanical testing device. Flexural loading was performed under a three-point loading test procedure with displacement-controlled flexural loading at a rate of $0.5 \mathrm{~mm}$ per minute for all mixtures. Displacement-controlled loading was applied using the displacement data obtained from a linear variable transformer placed under the midspan of the prismatic specimens. The displacement loading sequence was selected to observe any change in strain mechanism as the amount of kP-NES additive was increased. Testing the ultimate compressive strength was executed according to TS EN 196-1 (66). Also in line with the aforementioned standard, specimens cracked into halves under threepoint bending were used for compressive strength analysis. Specimens were placed between $40 \times 40 \mathrm{~mm}$ loading plates in the compressive testing apparatus. The compressive strength loading sequence was implemented at a speed of $0.5 \mathrm{MPa} / \mathrm{sec}$. Since failure detection mode was activated, specimens were compressed until a $20 \%$ decrease after the maximum compressive strength peak. All mechanical testing data were recorded at $10 \mathrm{~Hz}$ with an integrated data acquisition system. Flexural stresses and strain values for three-point loading were calculated from the Equations below [1] and [2]:

$$
\begin{gathered}
\sigma=\frac{3 P L}{2 b d^{2}} \\
\varepsilon=\frac{6 D d}{L^{2}}
\end{gathered}
$$

where $\sigma$ is the flexural stress, $\varepsilon$ is the flexural strain, $\mathrm{P}$ is the maximum flexural load, $\mathrm{D}$ is the maximum deflection at the midspan, $\mathrm{d}$ is the height and $b$ is the width, and $\mathrm{L}$ is the span length of the specimens.

\subsubsection{Rheological testing of the nanostructure}

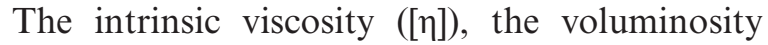
$\left(\mathrm{V}_{\mathrm{E}}\right)$, and the shape factor $(\mathrm{v})$ of the $\kappa$-carrageenan/ PVA/eggshell nanostructure were calculated to understand its rheological properties (Equations [3], [4], [5] and [6]). The viscosity analysis was performed for $50 \mathrm{ml}$ of the sample at $25 \pm 0.5^{\circ} \mathrm{C}$ and measured three times. The intrinsic viscosity was determined by measuring the values of the relative viscosity

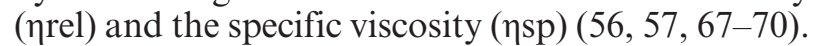
The Huggins parameters of intrinsic viscosity and model constant $(\mathrm{k})$ were calculated to understand the viscosity properties of the nanostructure.

$$
[\eta]=\frac{\eta_{\text {sp }}}{C}=\frac{\eta_{\text {rel }}-1}{C}=\frac{\frac{t}{t_{0}}-1}{C}
$$

where $t_{0}$ is the flow time of the pure solvent and $t$ is the flow time of the solution.

$$
\begin{gathered}
\eta_{\mathrm{sp}} / \mathrm{C}=[\eta]+\mathrm{k}[\eta]^{2} \mathrm{C} \\
{[\eta]=u V_{E}} \\
\gamma=\frac{\eta_{\mathrm{rel}}^{0.5}-1}{\mathrm{C}\left(1.35 \eta_{\mathrm{rel}}^{0.5}-0.1\right)}
\end{gathered}
$$

\section{RESULTS AND DISCUSSION}

\subsection{Characterization}

Zetasizer and scanning electron microscopy (SEM) analyses of the $\kappa$-carrageenan/PVA/ nanoeggshell nanostructure were performed for surface morphological characterization and are presented in Figure 1 at two magnifications (x-250 and $\mathrm{x}-5.000)$. The Zetasizer analysis measured the hydrodynamic diameter and surface potential of the $\kappa$-carrageenan/PVA/eggshell nanostructure. According to the results of this analysis, the $\kappa$-carrageenan/PVA/eggshell nanostructure exhibited a very good distribution and the hydrodynamic diameter and surface potential of the nanostructure were measured as $299.7 \mathrm{~nm}$ and $29.8 \mathrm{mV}$, respectively. According to the SEM results, the interaction and homogeneous distribution of the eggshell with the polymer mixture matrix on a nano-scale were clearly shown. The surface morphology of the eggshell had an irregular fiber shape (5000× magnification), which is in line with the literature $(71,72)$. The $\kappa$-carrageenan/PVA/eggshell nanostructure was in irregular shape and consisted of porous globular aggregates smaller than 1 micrometer. A previous study reported that the specific surface area of the eggshell modified with the ultrasonic effect was $9.84 \mathrm{~m}^{2} / \mathrm{g}(73)$. In this study, the surface area of the $\kappa$-carrageenan/PVA/eggshell nanostructure and unmodified eggshell were obtained as 129.9 $\mathrm{m}^{2} / \mathrm{g}$ and $6.27 \mathrm{~m}^{2} / \mathrm{g}$, respectively. The specific gravity of the $\kappa$-carrageenan/PVA/eggshell nanostructure is 1.80. Furthermore, the characterization results achieved in this study proved that the sonication method played a major role in the synthesis of high surface area $\mathrm{CaCO}_{3}$ nanoparticles, as stated in other studies $(73,74)$. 

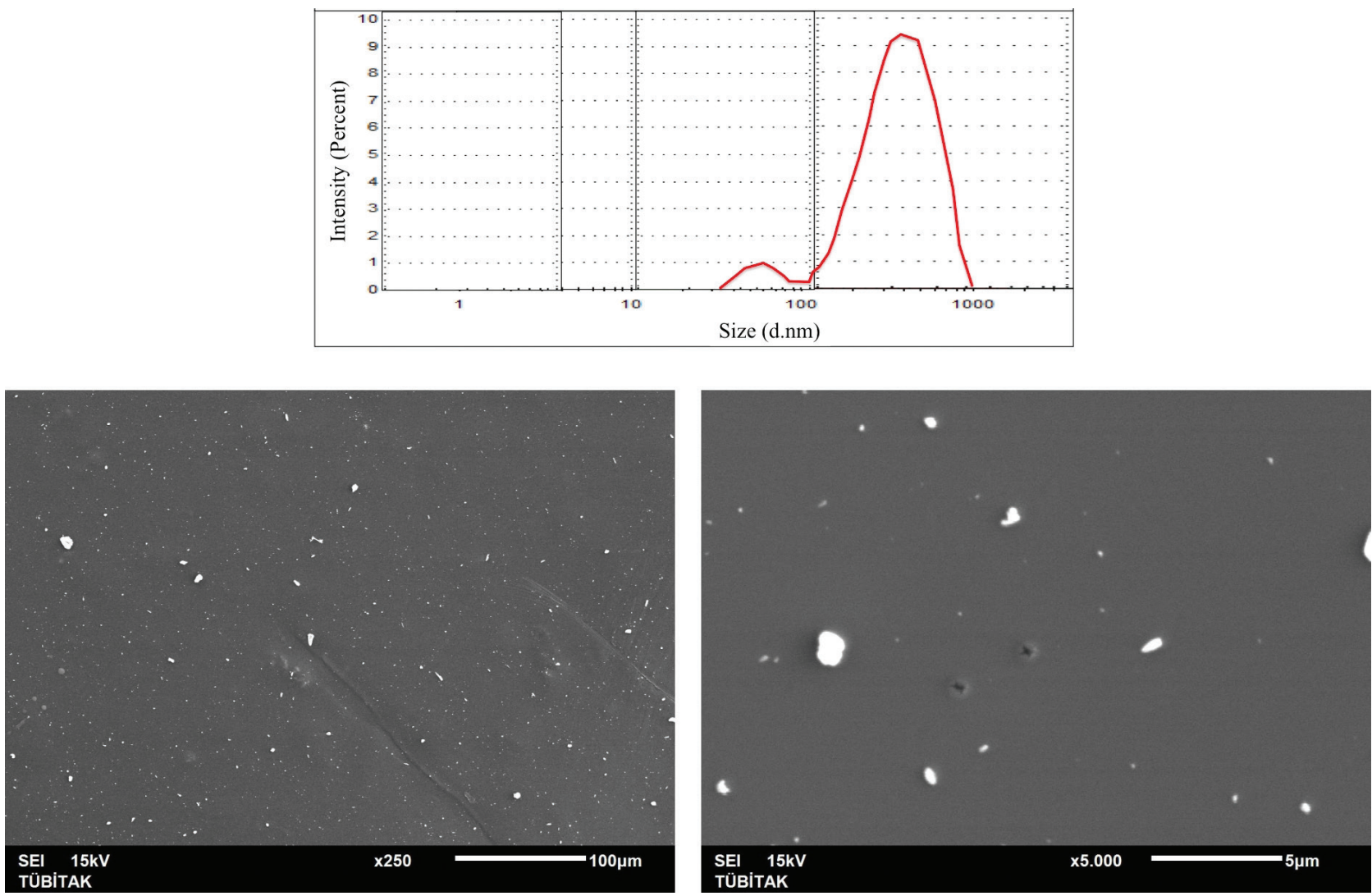

FIGURE 1. SEM micrographs and particle size for $\kappa$-carrageenan/PVA/eggshell nanostructure at two magnifications (x-250 and $\mathrm{x}-5.000)$.

A FTIR analysis was used to study the chemical characterization of all samples. In Figure 2, a FTIR spectrum of the $\kappa$-carrageenan/PVA/nanoeggshell nanostructure is presented. FTIR peaks of $\kappa$-carrageenan/PVA/nanoeggshell nanostructure were observed at $3400 \mathrm{~cm}^{-1}-3199 \mathrm{~cm}^{-1}$ (-OH functional groups), $2913 \mathrm{~cm}^{-1}-2856 \mathrm{~cm}^{-1}$ (-CH stretching), $1726 \mathrm{~cm}^{-1}-1640 \mathrm{~cm}^{-1}$ ( $\mathrm{C}=\mathrm{O}$ groups $), 1455 \mathrm{~cm}^{-1}$, $1412 \mathrm{~cm}^{-1}, 1369 \mathrm{~cm}^{-1}, 1100 \mathrm{~cm}^{-1}$ and $1050 \mathrm{~cm}^{-1}$ due to $\mathrm{C}=\mathrm{O}$ bonds from carbonates. The FTIR peaks of the carbonate groups obtained here are similar to the results reported in the literature $(75,76)$. Results showed that the eggshells and $\kappa$-carrageenan/PVA had a chemical interaction due to the $-\mathrm{OH}$ and $\mathrm{C}=\mathrm{O}$ groups.

\subsection{Viscosity studies}

Determining the rheological property of the $\kappa$-carrageenan/PVA/eggshell nanostructure is a major factor in understanding its physical properties. The physicochemical parameters such as small dimensions, shapes, homogeneous distribution and stability of nanosystems play a significant role in increasing the performance of new materials (77-80). In order to characterize the rheological

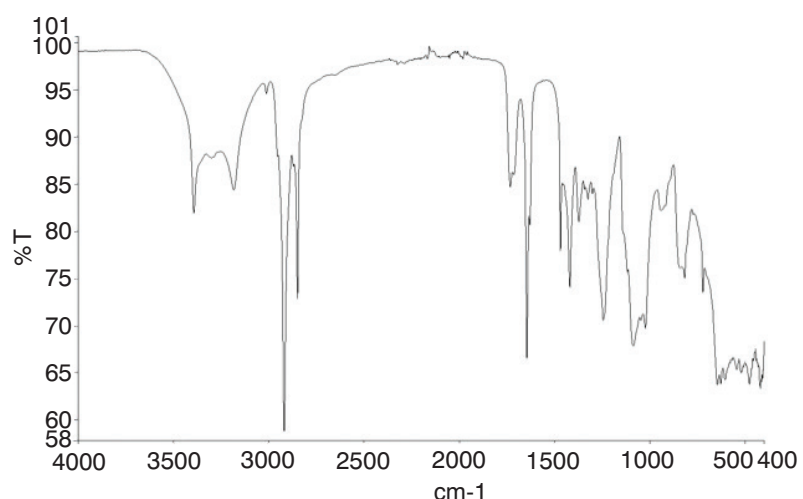

FIGURE 2. FTIR spectrum of $\kappa$-carrageenan/PVA/ nanoeggshell nanostructure.

properties of nanodispersions, the viscosity of nanodispersions needs to be measured and these physicochemical parameters need to be calculated $(56,81)$.

In order to obtain a homogenous nanostructure, synthesized materials were examined in different conditions such as polymer blend ratios, salt effect and sonication time. Rheological parameters $[\eta]$, volumetric $\left(V_{E}\right)$ and shape factor $(v)$ of the 
nanoeggshell were calculated using Huggins models with a high correlation constant $\left(\mathrm{R}^{2}\right)$.

In this study, $\kappa-N E S$, P-NES and kP-NES solutions were prepared to take measurements in rheological analysis. Besides, kP-NES consisting of binary polymer mixtures was prepared in different volumetric ratios (v/v) $(1: 1,1: 2$ and 1:3). Viscosity measurements of different formulations kP-NES and $\kappa-N E S, P-N E S$ solutions were analyzed at room temperature. Figure 3 presents the changes in $[\eta]$ in different formulations of $\mathrm{kP}-\mathrm{NES}(\mathrm{v} / \mathrm{v})(1: 1,1: 2$, 1:3), P-NES and $\kappa-N E S$.

The intrinsic viscosities of kP-NES (v/v) (1:1, 1:2, $1: 3), \kappa-N E S$ and P-NES were calculated using the Huggins model with a high correlation constant $\left(\mathrm{R}^{2}\right)$, and the results were $0.9957,0.9961,0.9890,0.990$ and 0.9923, respectively. According to the experimental measurements, kP-NES (1:1) homogeneous distribution was observed and precipitation was observed in solutions prepared in a 1:2 and 1:3 volume ratio. In a previous study, increasing the amount of biopolymer

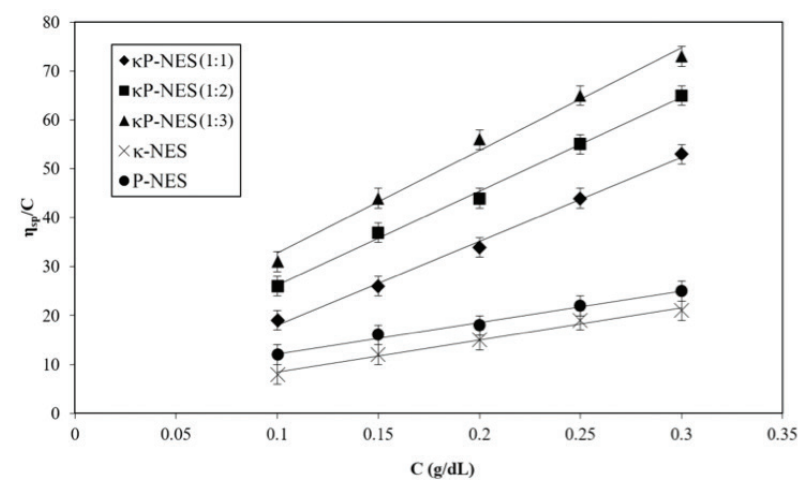

Figure 3. Huggins models of kP-NES (v/v) (1:1, 1:2, 1:3), $\kappa$-NES and P-NES. $\kappa$-carrageenan in the binary polymer system has proven to be advantageous in synthesizing a homogeneous nanostructure due to the interaction between the anionic sulfate groups on $\kappa$-carrageenan and the hydroxyl groups of PVA (50).

The viscosity measurements were continued with the kP-NES (1:1) nanoformulation. Figure 4 presents the changes in [ $\eta]$ at different sonication times for kP-NES (1:1). This variation in the rheological parameters was justified by using the Huggins model with a high correlation constant $\left(\mathrm{R}^{2}\right)$. As sonication time increased, the intrinsic viscosities of $\kappa \mathrm{P}-\mathrm{NES}$ (v/v) $(1: 1,1: 2,1: 3), \kappa-N E S$ and P-NES decreased. The Huggins parameters for $\kappa \mathrm{P}-\mathrm{NES}$ are compared across different sonication times in Table 2. The intrinsic viscosities of the samples synthesized at different sonication times $(10 \mathrm{~min}, 30 \mathrm{~min}$, and $1 \mathrm{~h})$ were calculated using the Huggins model with a high correlation constant $\left(\mathrm{R}^{2}\right)$, and these results were 0.9922 for $10 \mathrm{~min}, 0.9861$ for $30 \mathrm{~min}$, and 0.9957 for $1 \mathrm{~h}$ (Table 2).

According to the experimental data, the value of $[\eta]$ decreased with increasing sonication time by employing the Huggins model (Table 2). kP-NES was found to have the lowest $[\eta]$ value at $1 \mathrm{~h}$ sonication time. Previous research (82) reported that the sonication method, which is a green method, had an effect on viscosity and yielded a homogeneously dispersed nanostructure; the results of the current study are consistent with prior findings.

It has been reported in the literature that the shape of nanoparticles plays a major role in the mechanical behavior and performance of nanostructures $(83,84)$. In this study, and in line with the literature, the shape factor was determined by changing the physicochemical parameters. The viscosity method, which is a simple and economical technique, was used to determine the shape of the

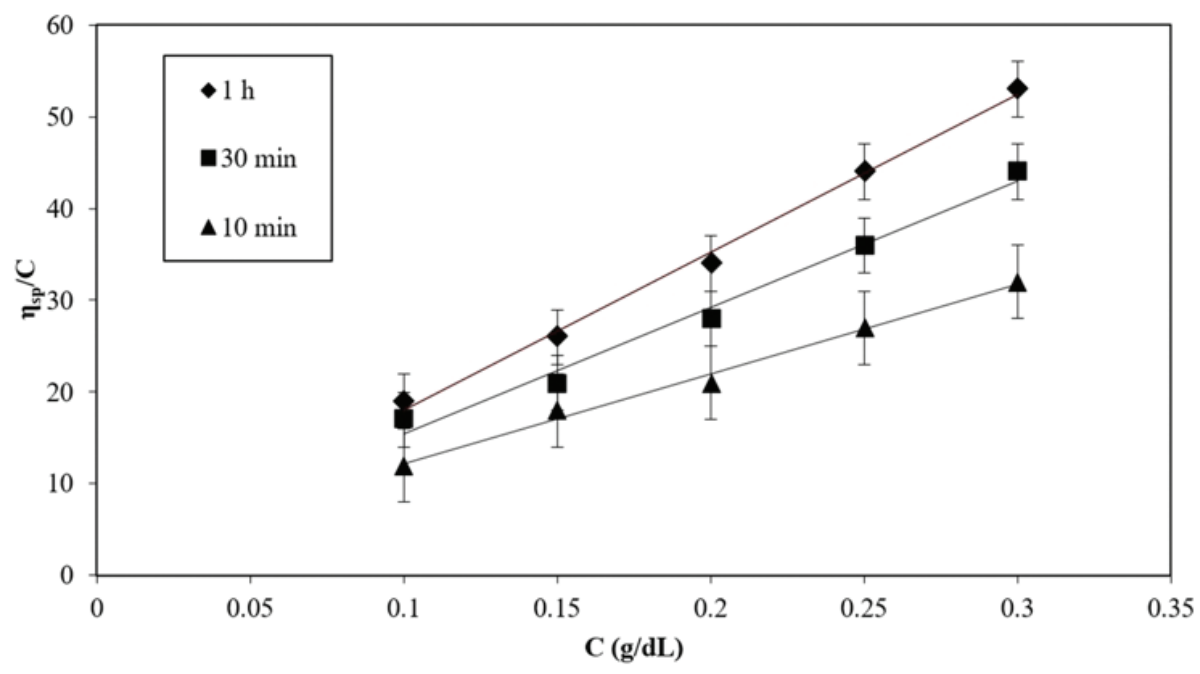

FIGURE 4. Huggins models of kP-NES with different sonication times. 
TABLE 2. Huggins parameters for $\mathrm{\kappa P}-\mathrm{NES}$.

\begin{tabular}{llr}
\hline Sonication time & \multicolumn{2}{c}{ Huggins model } \\
\hline $10 \mathrm{~min}$ & {$[\eta](\mathrm{d} 1 / \mathrm{g})$} & 2.4 \\
& $\mathrm{~b}$ & 268.75 \\
& $\mathrm{R}^{2}$ & 0.9922 \\
$30 \mathrm{~min}$ & {$[\eta](\mathrm{d} 1 / \mathrm{g})$} & 1.6 \\
& $\mathrm{~b}$ & 53.91 \\
& $\mathrm{R}^{2}$ & 0.9915 \\
$1 \mathrm{~h}$ & {$[\eta](\mathrm{d} 1 / \mathrm{g})$} & 0.8 \\
& $\mathrm{~b}$ & 17.01 \\
& $\mathrm{R}^{2}$ & 0.9957 \\
\hline
\end{tabular}

TABLE 3. Voluminosity and shape factors for kP-NES.

\begin{tabular}{lccc}
\hline Time & $\mathbf{V}_{\mathbf{E}}(\mathbf{d L} / \mathbf{g})$ & $\mathbf{v}$ & Shape \\
\hline $10 \mathrm{~min}$ & 2.23 & $2.5<$ & Spherical \\
$30 \mathrm{~min}$ & 1.45 & $2.5<$ & Spherical \\
$1 \mathrm{~h}$ & 1.02 & $2.5<$ & Spherical \\
\hline
\end{tabular}

*Values are means \pm standard deviation $(\mathrm{SD})$ for triplicate determination.

nanomaterial and, consequently, the optimization conditions required to obtain the specific characteristics of the nanomaterial. Shape factor (v) values were calculated for kP-NES and this value was calculated to be less than 2.5. Accordingly, it was considered that the structure had a spherical shape and that the volume of the sample $\left(\mathrm{V}_{\mathrm{E}}\right)$ decreased as the sonication time increased (Table 3).

In Figure 5, the change in [ $\eta$ ] at different concentrations of $\mathrm{NaOH}$ is given. The findings reveal that the $\kappa$-carrageenan/PVA/eggshell nanostructure had the lowest $[\eta]$ value at room temperature in $0.1 \mathrm{M}$ $\mathrm{NaOH}$ solution. It was found that the decrease in

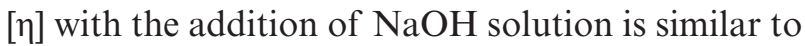
reports given in the literature (85).

\subsection{Flowability of mortar mixtures}

Flowability tests were carried out on 10 different mixtures; flow diameters are shown in Figure 6. The best results were observed in the specimens with additives incorporating $\kappa$-carrageenan. The increase in workability for all specimen configurations can be attributed to the use of nanoeggshell, since all specimens contain nanoeggshell particles. The use of both $\kappa$-carrageenan and nanoeggshell in the same combination seemed more effective. When mixtures of kP-NES and $\kappa$-NES were compared, the increasing $\mathrm{k}$ content had a bigger effect on the workability than did increasing PVA content. In addition, the results proved that PVA presence in additive formation adversely affected mixture workability. On the other hand, the contribution of the P-NES

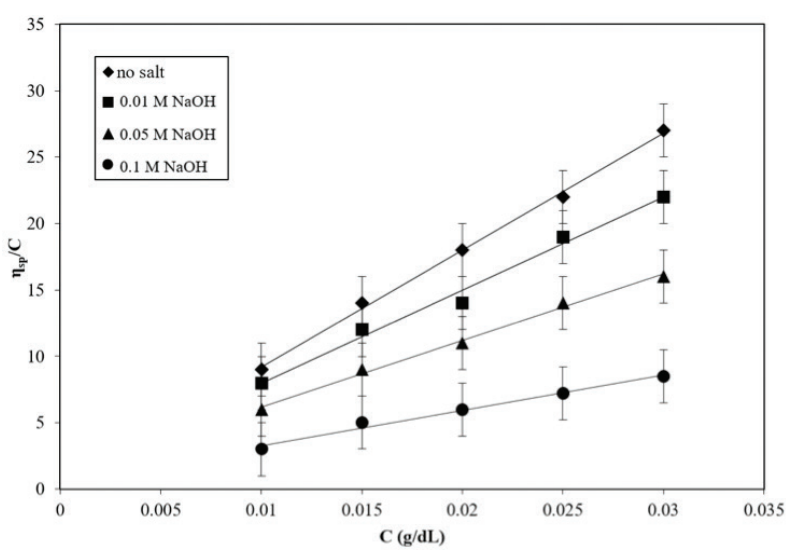

FiguRE 5. Huggins models of $\kappa$-carrageenan/PVA/eggshell nanostructure in different concentrations of $\mathrm{NaOH}$.

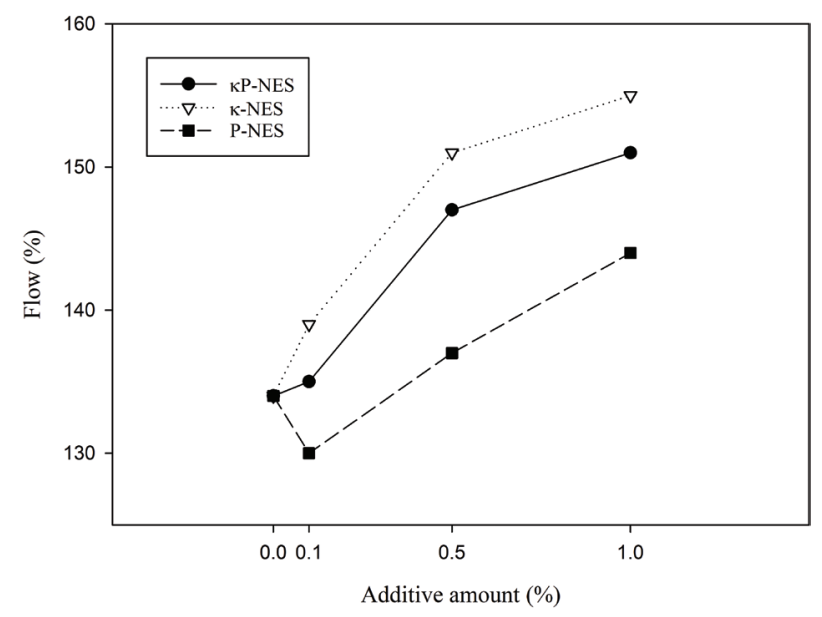

FIGURE 6. Flowability of all mixtures with the different additive amounts.

combination seemed to be lower relative to other specimen configurations, whereas in the literature PVA inclusion in mixtures resulted in an increase in workability, which was attributed to ball-bearing action and the dispersing effect of the PVA polymer (86). Therefore, the fact that better workability was found with k compared to PVA is an important contribution to the literature in light of earlier studies showing only an effect for PVA $(86,87)$. At the same time, in previous research by the current authors, nanoeggshell structure was found to be effective in increasing flowability of mixtures with similar compositions (22). Therefore, within this study, even though the improved results on workability seem to be due to $\mathrm{k}$, the observed increase could be mainly attributed to nanoeggshell inclusion.

When Figure 6 is inspected, it is evident that the increase in the diameters is related to the increase in the additive amount. Mixture series containing only $0.1 \%$ cement by binder had similar workability results with control specimens, but P-NES1 mixtures 
were the only series that were less workable than the control series. The $0.1 \%$ additive condition did not alter workability much; however, higher amounts like 0.5 and $1 \%$ enhanced workability properties and was found to be promising for creating a denser cement matrix.

\subsection{Mechanical tests}

Mechanical tests were carried out for each specimen to obtain the compressive and flexural strengths, and the results are given in Figures 7-10. Taken together, the findings of 7- and 28-day mechanical tests indicate that there was a clear improvement both in the compressive and flexural strength results for all the specimens containing the additives. The observed increase was satisfactory, especially in the compressive strength results of specimens with a higher amount of additives.

The 7- and 28-day compressive strength results are compared and illustrated in Figure 7 . For the specimens with a lower amount of additive $(0.1 \%)$, the inclusion of the additives does not appear to affect the ultimate compressive strength of the specimens. On the other hand, increasing additive content resulted in noticeable improvements in compressive strength; the largest improvement is observed for the kP-NES mixtures. kP-NES10 specimens attained an $11 \%$ increase in compressive strength, and this increase is the largest in the compressive strength results. $\kappa$-NES specimens exhibited superior performance with respect to P-NES specimens, which can be attributed to the improved workability of these specimens, which was also observed in flowability results. Higher workability should result in a more homogenous matrix structure in mortar specimens and correspondingly better mechanical properties. This result may be also claimed for kP-NES specimens since these specimens also contain $\mathrm{k}$ particles. The $\kappa-N E S$ results were very close to the results

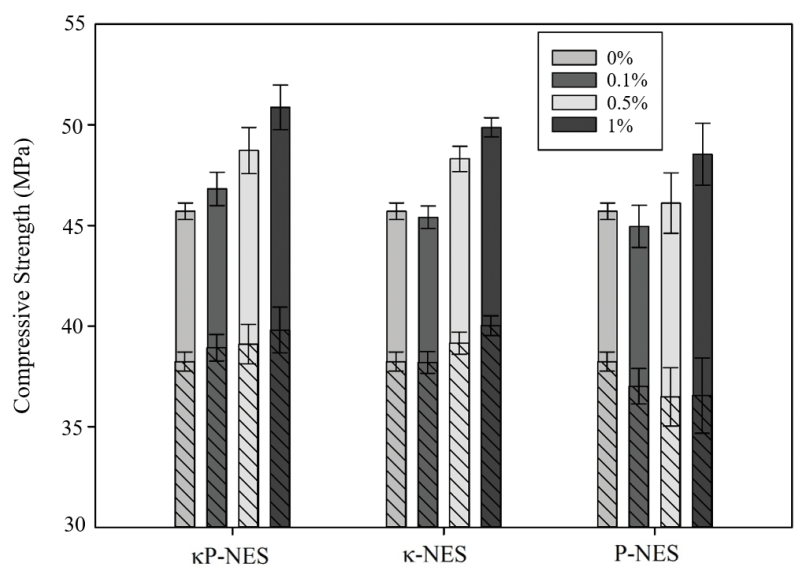

FIGURE 7. 7- and 28-day compressive strength results for all specimen series, with standard deviation error bars. for kP-NES, which can be asserted because PVA's contribution to compressive strength was comparatively low. Findings from previous research indicate that PVA modification in cement mortars caused a reduction in compressive strength (87). On the other hand, the improvements in the flexural strength of the PVA modified mortars were found to be sensitive to curing conditions and the water-to-cement ratio (86). When standard deviation values were inspected, P-NES specimens showed greater deviation, whereas the specimens that incorporated k particles showed better distribution. This behavior in the PVA containing mixtures may be related to more air voids formed after PVA inclusion (87). It may also be noted that lower deviations monitored for $\kappa$-NES specimens were similar to deviations derived from control specimens. Nanoparticles containing $\kappa$-carrageenan polymer seemed to be effective

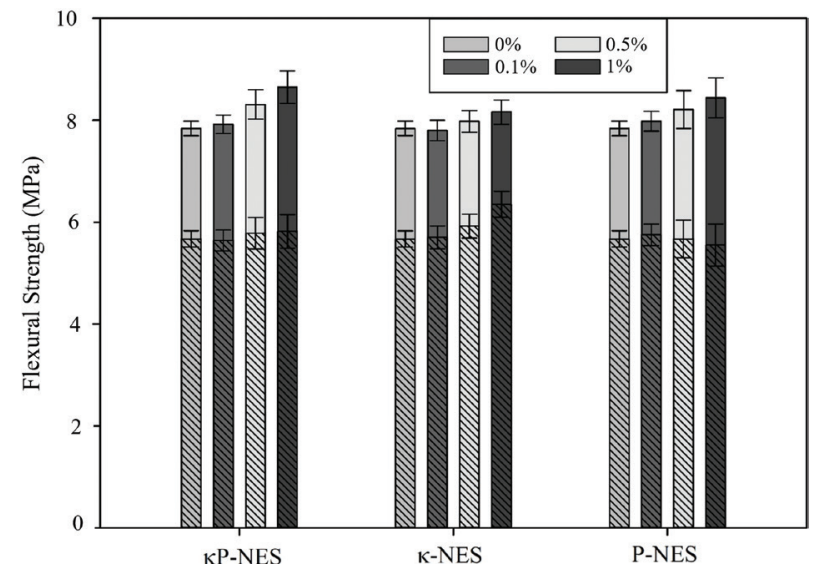

FIGURE 8. 7- and 28-day flexural strength results for all specimen series, with standard deviation error bars.

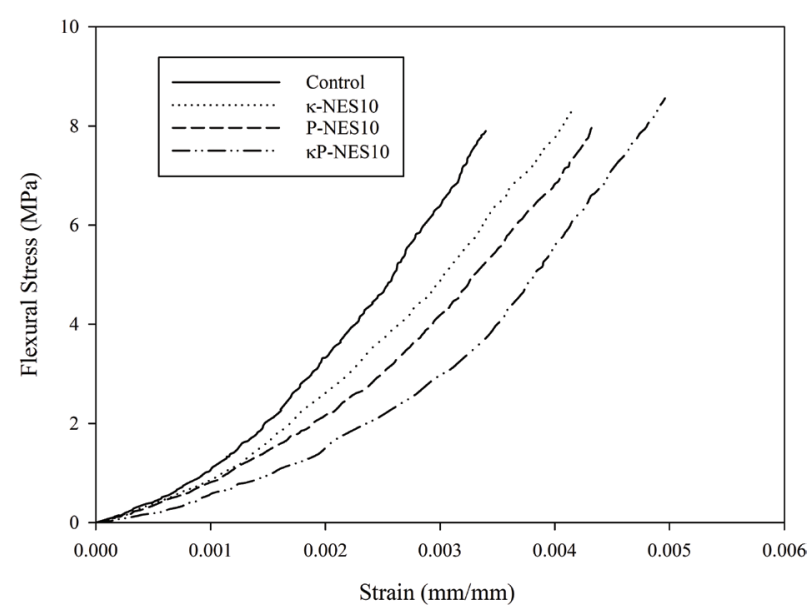

FIGURE 9. Flexural stress vs. strain curves for 4 different specimens from each set. 

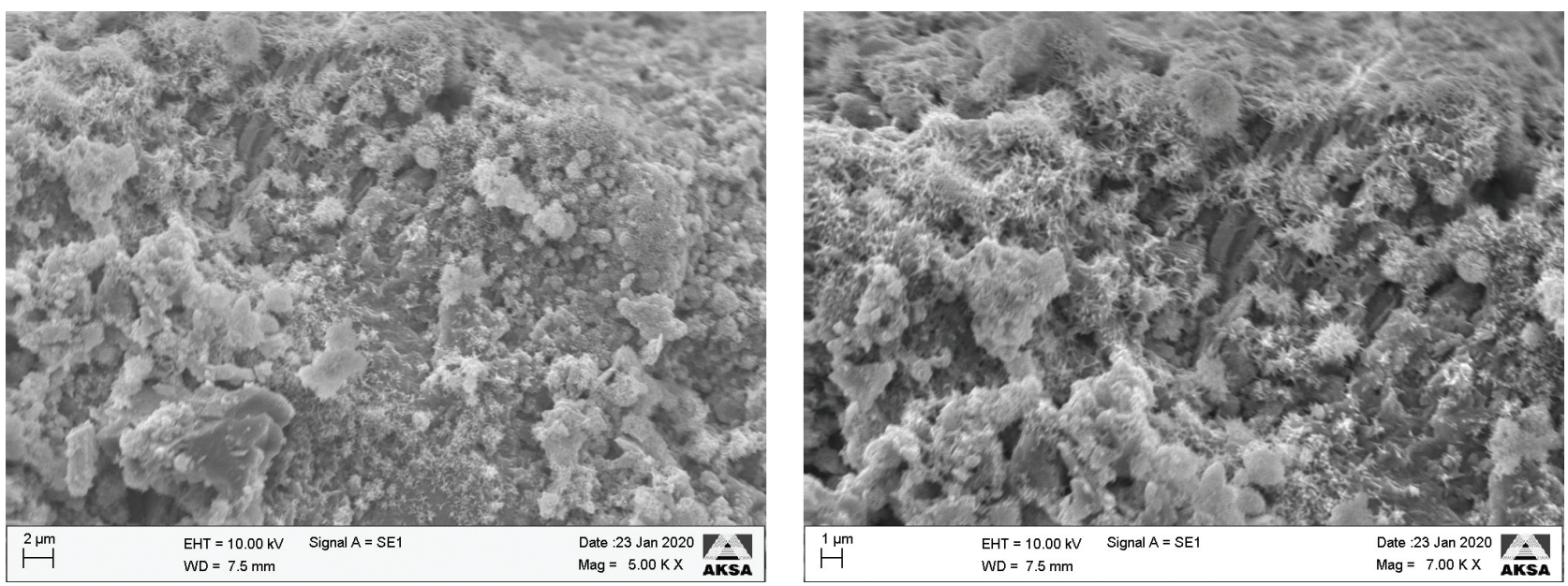

FIgURE 10. SEM analysis results for kP-NES10 specimens at (a) X 7000 (b) X 5000 magnification.

when dispersing in the cement matrix, subsequently enhancing the effect of nano-sized eggshell in the interfacial transition zone.

In terms of the 7-day compressive strength results, increasing the amount of additive did not affect the results, except for the P-NES specimens. For the P-NES specimens, increasing additive content had an adverse effect on early strength development. As illustrated in Figure 6, P-NES specimens exhibited lower workability features, which can be attributed to the decrement observed in the 7-day results. Having lower flowability induced more unhydrated particles in the early days and this most likely led to the delayed formation of hydration products in the P-NES specimens. However, a 28-day curing period seemed to be sufficient for decreasing the amount of unhydrated particles and enhancing the final mechanical properties of these specimens. Additionally, as the additive amount was increased the standard deviations for the 7-day results increased as well, especially for the P-NES specimens. For the control specimens, however, the standard deviations were smaller.

The results of the flexural tests for all specimen types and additive amounts are shown in Figure 8 for both 7 and 28 days. As can be seen, the 28-day flexural test results were found to be affected by the increasing additive amount. The results for the specimens containing $0.1 \%$ additive are very similar to the results for the control specimens. As for specimens incorporating PVA particles, they displayed superior flexural performance with respect to the control specimens. Moreover, similar to the results of the compressive strength test, the kP-NES10 specimens had a $10.32 \%$ increase in flexural strength. On the other hand, P-NES specimens exhibited an increase of $7.65 \%$, resulting in a higher level of improvement in flexural strength compared to compressive strength, which is consistent with previous studies $(86,88)$. Specimens with higher additive amounts showed larger deviations with respect to the control specimens. Deviations in the flexural results was observed to be generally higher than the deviations in the compressive strength results.

The 7-day flexural strength results given in Figure 8 confirm that no significant alterations were observed in the early flexural strength results. The results for the three specimen series are similar to the control specimens, and the standard deviation values are similar as well. Here, the clear distinction between the 7-day and 28-day specimens may be related to the fact that adding $\kappa$-carrageenan during cement hydration slows the release of the ionic pore solution, serving as an internal curing agent (49).

Flexural stress-strain curves for the control specimen and three specimen series with the higher additive amounts are compared in Figure 9. From each specimen set, the flexural stress-strain curve of one specimen closest to the average maximum strain value is given. When the control specimen is compared with the other specimen sets, it is apparent that additive inclusion significantly increased the strain capability under bending stresses.

The average maximum strain values for all specimens in each series are given in Table 4. Higher strain capability is an important issue for cementitious materials since concrete is inherently weak under tensile loads. The data in the table show that as amount of additive is increased, the deformation capacity of the beams under bending increases. Therefore, a notable feature of this study is that all specimens displayed ductile behavior under stresses due to the existence of the novel synthesized nanoeggshell (22). It was demonstrated that the incorporation of several nanoparticles increased strain capacity by delaying the initiation of microcracks in the cement 
TABLE 4. Averages of maximum strain values under bending.

\begin{tabular}{|c|c|}
\hline Specimen Series & $\begin{array}{c}\text { Average Maximum Strain } \\
(\mathrm{mm} / \mathrm{mm})\end{array}$ \\
\hline Control & 0.003365 \\
\hline$\kappa \mathrm{P}-\mathrm{NES} 10$ & 0.005050 \\
\hline кP-NES5 & 0.004301 \\
\hline$\kappa-\mathrm{NES} 10$ & 0.004345 \\
\hline$\kappa-N E S 5$ & 0.003941 \\
\hline P-NES10 & 0.004210 \\
\hline P-NES5 & 0.003910 \\
\hline
\end{tabular}

matrix; this result was found in previous research as well (89). Moreover, among all the combinations, the kP-NES specimens were revealed to be the best combination with the improved results in compressive and flexural strength analyses. The strain values of the $\kappa$-NES and P-NES specimens were found to be very close to each other. In general, it should be noted that the $\mathrm{kP}-\mathrm{NES}$ specimens showed a $48 \%$ higher strain capacity under bending forces coupled with a $10 \%$ increase in ultimate flexural strength. Therefore, considerable insight has been gained in terms of strain capacity and flexural strength with regard to the use of all three additives together in cementitious composites.

\subsection{Microstructural investigation of mortar specimens}

Figure 10 shows the SEM micrographs for the kP-NES specimens. When the mechanical properties were examined, the best performance was detected for the kP-NES specimens. In SEM visualizations, more homogenous C-S-H formation was observed, which was probably the result of better dispersed nanoeggshell particles, an advantage that emerges from the synthesized $\mathrm{k}$ particles. In the literature, nanoparticles are reported as having a high specific surface area, which reflects an enhanced hydration process and consequently a better dispersion of C-S-H particles (80). In the current study, a synthesis of a novel nanocomposite containing $\kappa$-carrageenan, PVA and eggshell particles demonstrated that the nanocomposite is a suitable combination for creating an ultra-high specific surface area via the likely creation of improved bonding within the interfacial transition zone.

The improved dispersion of C-S-H particles was noted to be effective in mortar specimens. Hence, in the visual scanning in SEM observations, more homogenous C-S-H formation was observed. When interfacial transition zones were investigated, the $\mathrm{Ca} / \mathrm{Si}$ ratios of $\mathrm{C}-\mathrm{S}-\mathrm{H}$ particles were found to be higher compared to control specimens. Better workability has probably led to better formation of the inner structure, creating a more compact matrix. Additionally, as seen in Figure 10, different configurations of C-S-H structure were detected when kPNES specimens were investigated by SEM analysis. Here, more fibrous types of C-S-H were detected, which may be related to better nanocomposite structure that was formed through the novel synthesis of $\kappa$-carrageenan, PVA and eggshell particles.

\section{CONCLUSIONS}

In this study, a novel к-carrageenan/PVA/eggshell nanostructure was prepared via a green sonication method and characterized using FTIR, SEM, BET and Zetasizer techniques. The viscometer technique was used to calculate the intrinsic viscosity, voluminosity, and shape factor of the nanoeggshell.

Regarding the workability of the mortar mixtures, the $\kappa$-NES mixture which is the combination of nanoeggshell formulation and $\mathrm{k}$ particles was observed to be effective. A similar advantage was also detected for the triple combination kP-NES specimens. These findings can be interpreted as the positive effect of $\mathrm{k}$ on the workability of the mixtures, similar to the effect of nanoeggshell.

The mechanical tests revealed that both compressive and flexural strengths increased for kP-NES10, the triple combination with $1 \%$ additive content, at a rate of $11 \%$ and $10 \%$, respectively. Another noteworthy result to emerge from the data is that the maximum strain capacity of all specimens with additives was better than that of the control specimens, and thus the ductility of the mortar prisms under bending stresses were improved. Among all the additive combinations, the triple combination specimens, kP-NES specimens, were found to be the best practice. It is very likely that the $\mathrm{k}$ and PVA particles in the nanoeggshell in the triple combination may have led to efficient dispersion in the cement matrix, which in turn brought positive changes in overall performance. For all three types of additive, the results reported were superior compared to control specimens; however, $0.1 \%$ inclusion of additive content was not found to be sufficient for enhancing any properties of mortar specimens.

This study is the first attempt to use the innovative $\kappa$-PVA-nanoeggshell combinations in mortar mixture specimens, and results so far can be interpreted as a very promising improvement for concrete technology. In addition to the increase in compressive and flexural strength, the decisive advantage of the presented nano-mixture is the enhanced strain capacity. Therefore, this study presents a viable alternative to the environmentally-friendly nanomixtures that can be produced on an industrial scale. It is hoped that the prospect of being able to use the nano-mixture proposed in this study for cementitious composites will spur future work on 
using differently synthesized alternative additives in concrete technology.

\section{ACKNOWLEDGEMENTS}

The authors gratefully acknowledge AKKİM for the technical support and AKÇANSA for the material supply.

\section{REFERENCES}

1. Hesami, S.; Ahmadi, S.; Nematzadeh, M. (2014) Effects of rice husk ash and fiber on mechanical properties of pervious concrete pavement. Constr. Build. Mater. 53, 680-691. https://doi.org/10.1016/j.conbuildmat.2013.11.070

2. Aksoğan, O.; Binici, H.; Ortlek, E. (2016) Durability of concrete made by partial replacement of fine aggregate by colemanite and barite and cement by ashes of corn stalk, wheat straw and sunflower stalk ashes. Constr. Build. Mater. 106, 253-263. https://doi.org/10.1016/j.conbuildmat.2015.12.102.

3. Sada, B.H.; Amartey, Y.D.; Bako, S. (2013) An Investigation into the Use of Groundnut Shell as Fine Aggregate Replacement. Niger. J. Technol. 32, 54-60.

4. Olanipekun, E.A.; Olusola, K.O.; Ata, O. (2006) A comparative study of concrete properties using coconut shell and palm kernel shell as coarse aggregates. Build. Environ. 41, 297-301. https://doi.org/10.1016/j. buildenv.2005.01.029.

5. Pliya, P.; Cree, D. (2015) Limestone derived eggshell powder as a replacement in Portland cement mortar. Constr. Build. Mater. 95, 1-9. https://doi.org/10.1016/j.conbuildmat. 2015.07.103.

6. Mine, Y. (2008) Egg Bioscience and Biotechnology. John Wiley \& Sons, Inc. (2008).

7. Rivera, E.M.; Araiza, M.; Brostow, W.; Castaño, V.M.; Díaz-Estrada, J.R.; Hernández, R.; Rodríguez, J.R. (1999) Synthesis of hydroxyapatite from eggshells. Mater. Lett. 41, 128-134. https://doi.org/10.1016/S0167-577X(99)00118-4.

8. Beck, K.; Brunetaud, X; Mertz, J.D; Al-Mukhtar, M. (2010) On the use of eggshell lime and tuffeau powder to formulate an appropriate mortar for restoration purposes. Geol. Soc. Spec. Publ. 331, 137-145. https://doi.org/10.1144/ SP331.12.

9. Freire, M.N.; Holanda, J.N.F.; (2006) Characterization of avian eggshell waste aiming its use in a ceramic wall tile paste. Cerâmica. 52, 240-244. https://doi.org/10.1590/ s0366-69132006000400004.

10. Siqueira, F.B.; Amaral, M.C.; Bou-Issa, R.A.; Holanda, JN.F. (2016) Influence of industrial solid waste addition on properties of soil-cement bricks. Cerâmica. 62, 237-241. https://doi.org/10.1590/0366-69132016623631969.

11. Sola, O.C.; Atis, C.D. (2012) The effects of pyrite ash on the compressive strength properties of briquettes. KSCE J. Civ. Eng. 16, 1225-1229. https://doi.org/10.1007/ s12205-012-1493-9.

12. Shiferaw, N.; Habte, L.; Thenepalli, T; Ahn, J.W. (2019) Effect of eggshell powder on the hydration of cement paste. Materials. 12, 2483. https://doi.org/10.3390/ ma12152483.

13. Tiong, H.Y.; Lim, S.K.; Lee, Y.L.; Lim, J.H. (2018) Engineering properties of $1200 \mathrm{~kg} / \mathrm{m}^{3}$ lightweight foames concrete with egg shell powder as partial replacement material of cement. E3S Web Conf. 65, 02010. https://doi.org/ $10.1051 / \mathrm{e} 3$ sconf $/ 20186502010$

14. Gowsika, D.; Sarankokila, S.; Sargunan, K. (2014) Experimental investigation of egg shell powder as partial replacement with cement in concrete. Int. J. Eng. Trends Technol. 14, 65-68. https://doi.org/10.14445/22315381/ ijett-v14p214.

15. Yerramala, A. (2014) Properties of concrete with eggshell powder as cement replacement. Indian Concr. J. 88, 94-102.
16. Ujin, F.; Ali, K.S.; Harith, Z.Y.H. (2017) The effect of eggshells ash on the compressive strength of concrete. Key Eng. Mater. 728, 402-407. https://doi.org/10.4028/www.scientific.net/KEM.728.402.

17. Patel, P.S.; Parikh, K.B.; Darji, A.R. (2017) Study on concrete using fly ash, rice husk ash and egg shell powder. Int. J. Res. Appl. Sci. Eng. Technol. 5, 566-570. https://doi. org/10.22214/ijraset.2017.2084.

18 Rahman, A.F: Goh, W.I; Mohamad, N.; Kamarudin, M.S.; Jhatial, A.A. (2019) Numerical analysis and experimental validation of reinforced foamed concrete beam containing partial cement replacement. Case Stud. Constr. Mater. 11, e00297. https://doi.org/10.1016/j.cscm.2019. e00297.

19. Zheng, B.; Qian, L.; Yuan, H.; Xiao, D.; Yang, X.; Paau, M.C.; Choi, M.M.F. (2010) Preparation of gold nanoparticles on eggshell membrane and their biosensing application. Talanta. 82, 177-183. https://doi.org/10.1016/j.talanta. 2010.04.014

20. Cui, T.-L.; He, J.-Y.; Liu, C.-S. (2020) High electrochemical performance carbon nanofibers with hierarchical structure derived from metal-organic framework with natural eggshell membranes. J. Colloid Interface Sci. 560, 811-816. https://doi.org/10.1016/j.jcis.2019.11.008.

21. Khan, S.R.; Jamil, S.; Ali, S.; Khan, S.A.; Mustaqeem, M.; Janjua, M.R.S.A. (2020) Synthesis and structure of calcium-tin hybrid microparticles from eggshell and investigation of their thermal behavior and catalytic application. Chem. Phys. 530, 110613. https://doi.org/10.1016/j.chemphys.2019.110613.

22. Pehlivan, A.O.; Karakuş, S.; Sanrı Karapınar, I.; Özsoy Özbay, A.E.; Yazgan, A.U.; Taşaltın, N.; Kilislioğlu, A. (2020) Effect of novel synthesized nanoeggshell on the properties of cementitious composites. J. Adv. Concr. Technol. 18, 294-306. https://doi.org/10.3151/jact.18.294.

23. Ahmed, E.M. (2015) Hydrogel: Preparation, characterization, and applications: A review. J. Adv. Res. 6, 105-121. https://doi.org/10.1016/j.jare.2013.07.006.

24. Warson, H. (2000) Modern superabsorbent polymer technology. Polym. Int. 49, 1548-1548.

25. Justs, J.; Wyrzykowski, M.; Winnefeld, F.; Bajare, D.; Lura, P. (2014) Influence of superabsorbent polymers on hydration of cement pastes with low water-to-binder ratio: A calorimetry study. J. Therm. Anal. Calorim. 115, 425-432. https://doi.org/10.1007/s10973-013-3359-x.

26. Kantro, D. (1980) Influence of water-reducing admixtures on properties of cement paste-A miniature slump test. Cem. Concr. Aggreg. 2, 95-102. https://doi.org/10.1520/ cca10190j.

27. Pourjavadi, A.; Harzandi, A.M.; Hosseinzadeh, H. (2004) Modified carrageenan 3. Synthesis of a novel polysaccharide-based superabsorbent hydrogel via graft copolymerization of acrylic acid onto kappa-carrageenan in air. Eur. Polym. J. 40, 1363-1370. https://doi.org/10.1016/j. eurpolymj.2004.02.016.

28. Krafcik, M.J.; Erk, K.A. (2016) Characterization of superabsorbent poly (sodium-acrylate acrylamide) hydrogels and influence of chemical structure on internally cured mortar. Mater. Struct. 49, 4765-4778. https://doi.org/10.1617/ s11527-016-0823-7.

29. Mitsuiki, M.; Yamamoto, Y.; Mizuno, A.; Motoki, M. (1998) Glass transition properties as a function of water content for various low-moisture galactans. J. Agric. Food Chem. 46, 3528-3534 https//doi.org/10.1021/jf9709820.

30. Scriven, F. (1994) The glassy state in foods. Trends Food Sci. Technol. 5, 176. https://doi.org/10.1016/0924-2244(94) 90128-7.

31. Chronakis, I.S.; Piculell, L.; Borgström, J. (1996) Rheology of kappa-carrageenan in mixtures of sodium and cesium iodide: two types of gels. Carbohydr. Polym. 31, 215-225. https://doi.org/10.1016/S0144-8617(96)00117-8.

32. Liu, S.; Li, L. (2016) Thermoreversible gelation and scaling behavior of $\mathrm{Ca}^{2+}$-induced $\kappa$-carrageenan hydrogels. Food Hydrocoll. 61, 793-800. https://doi.org/10.1016/j.foodhyd. 2016.07.003. 
33. Therkelsen, G.H. (1993) Carrageenan. In Industrial Gums: Polysaccharides and Their Derivatives: Third Edition. Elsevier Inc. 145-180. https://doi.org/10.1016/B978-0-08092654-4.50011-5.

34. Mechtcherine, V.; Gorges, M.; Schroefl, C; Assmann, A.; Brameshuber, W.; Ribeiro, A.B.; Cusson, D.; Custódio, J.; da Silva, E.F.; Ichimiya, K. et al. (2014) Effect of internal curing by using superabsorbent polymers (SAP) on autogenous shrinkage and other properties of a high-performance fine-grained concrete: results of a RILEM round-robin test. Mater. Struct. 47, 541-562. https://doi.org/10.1617/ s11527-013-0078-5.

35. Plank, J.; Sachsenhauser, B. (2009) Experimental determination of the effective anionic charge density of polycarboxylate superplasticizers in cement pore solution. Cem. Concr. Res. 39, 1-5 https://doi.org/10.1016/j.cemconres. 2008.09.001

36. Wang, F.; Zhou, Y.; Peng, B.; Liu, Z.; Hu, S. (2009) Autogenous shrinkage of concrete with super-absorbent polymer. ACI Mater. J. 106, 123-127. https://doi.org/10. $14359 / 56458$.

37. Campo, V.L.; Kawano, D.F.; da Silva Jr., D.B.; Carvalho, I. (2009) Carrageenans: Biological properties, chemical modifications and structural analysis - A review. Carbohydr. Polym. 77, 167-180. https://doi.org/10.1016/j. carbpol.2009.01.020.

38. Ling, Y.; Zhang, P.; Wang, J.; Chen, Y. (2019) Effect of PVA fiber on mechanical properties of cementitious composite with and without nano-SiO ${ }_{2}$. Constr. Build. Mater. 229, 117068. https://doi.org/10.1016/j.conbuildmat. 2019.117068.

39. Zhang, P.; Li, Q-f.; Wang, J.; Shi, Y.; Ling, Y-f. (2019) Effect of PVA fiber on durability of cementitious composite containing nano-SiO ${ }_{2}$. Nanotechnol. Rev. 8 [1], 116-127. https://doi.org/10.1515/ntrev-2019-0011

40. Zhang, P.; Li, Q.; Wang, J.; Shi, Y.; Zheng, Y.; Ling, Y. (2020). Effect of nano-particle on durability of polyvinyl alcohol fiber reinforced cementitious composite. Sci. Adv. Mater. 12 [2], 249-262. https://doi.org/10.1166/ sam. 2020.3680.

41. Ling, Y.F.; Zhang, P.; Wang, J.; Shi, Y. (2020) Effect of sand size on mechanical performance of cement-based composite containing PVA fibers and nano- $\mathrm{SiO}_{2}$. Materials. 13 [2], 325. https://doi.org/10.3390/ma13020325.

42. Tang, M-x.; Zhu, Y-d.; Li, D.; Adhikari, B.; Wang, L-j. (2019) Rheological, thermal and microstructural properties of casein/к-carrageenan mixed systems. LWT. 113, 108296. https://doi.org/10.1016/j.lwt.2019.108296.

43. Madruga, L.Y.C.; Sabino, R.M.; Santos, E.C.G.; Popat, K.C.; Balaban, R. de C.; Kipper, M.J. (2020) Carboxymethyl-kappa-carrageenan: A study of biocompatibility, antioxidant and antibacterial activities. Int. J. Biol. Macromol. 152, 483-491. https://doi.org/10.1016/j. ijbiomac.2020.02.274

44. Liu, Y.; Zhang, X.; Li, C.; Qin, Y.; Xiao, L.; Liu, J. (2020) Comparison of the structural, physical and functional properties of $\kappa$-carrageenan films incorporated with pomegranate flesh and peel extracts. Int. J. Biol. Macromol. 147, 1076-1088. https://doi.org/10.1016/j. ijbiomac.2019.10.075.

45. Berton, S.B.R.; de Jesus, G.A.M.; Sabino, R.M.; Monteiro, J.P.; Venter, S.A.S.; Bruschi, M.L.; Popat, K.C.; Matsushita, M.; Martin, A.F.; Bonafé, E.G. (2020) Properties of a commercial $\kappa$-carrageenan food ingredient and its durable superabsorbent hydrogels. Carbohydr. Res. 487, 107883. https://doi.org/10.1016/j.carres.2019.107883.

46. Azizi, S.; Mohamad, R.; Rahim, R.A.; Mohammadinejad, R.; Ariff, A.B. (2017) Hydrogel beads bio-nanocomposite based on Kappa-Carrageenan and green synthesized silver nanoparticles for biomedical applications. Int. J. Biol. Macromol. 104, 423-431. https://doi.org/10.1016/j. ijbiomac.2017.06.010.

47. Campanella, L.; Favero, G.; Persi, L.; Tomassetti, M. (2000) New biosensor for superoxide radical used to evidence molecules of biomedical and pharmaceutical interest having radical scavenging properties. J. Pharmac. Biomed. Anal. 23, 69-76. https://doi.org/10.1016/ S0731-7085(00)00276-4.

48. Spagnuolo, P.A.; Dalgleis, D.G.; Goff, H.D.; Morris, E.R. (2005) Kappa-carrageenan interactions in systems containing casein micelles and polysaccharide stabilizers. Food Hydrocoll. 19, 371-377. https://doi.org/10.1016/j. foodhyd.2004.10.003

49. Aday, A.N.; Osio-Norgaard, J; Foster, K.E.O.; Srubar III, W.V. (2018) Carrageenan-based superabsorbent biopolymers mitigate autogenous shrinkage in ordinary portland cement. Mater. Struct. 51, 37. https://doi.org/10.1617/ s11527-018-1164-5.

50. Mahdavinia, G.R.; Massoudi, A.; Baghban, A.; Shokri, E. (2014) Study of adsorption of cationic dye on magnetic kappa-carrageenan/PVA nanocomposite hydrogels. $J$. Environ. Chem. Eng. 2, 1578-1587. https://doi.org/10.1016/j. jece.2014.05.020.

51. Hezaveh, H.; Muhamad, I.I. (2013) Controlled drug release via minimization of burst release in $\mathrm{pH}$-response kappa-carrageenan/polyvinyl alcohol hydrogels. Chem. Eng. Res. Des. 91, 508-519. https://doi.org/10.1016/j. cherd.2012.08.014.

52. Esmaeili, C.; Heng, L.Y.; Ling, Y.P.; Norouzi, P.; Ling, T.L. (2017) Potentiometric urea biosensor based on immobilization of urease in Kappa-Carrageenan biopolymer. Sens. Lett. 15, 851-857. https://doi.org/10.1166/sl.2017.3882.

53. Li, J.-X.; Liu, D.; Qin, Z.-B.; Dong, G.-Y. (2019) Sonochemical synthesis of two nano-sized nickel(II) coordination polymers derived from flexible bis(benzimidazole) and isophthalic acid ligands. Polyhedron. 160, 92-100. https://doi.org/10.1016/j.poly.2018.12.029

54. Xu, H.; Zeiger, B.W.; Suslick K.S. (2013) Sonochemical synthesis of nanomaterials. Chem. Soc. Rev. 42, 2555-2567. https://doi.org/10.1039/c2cs35282f.

55. Tan, E.; Karakus, S.; Soylu, G.S.P.; Birer, Ö.; Zengin, Y.; Kilislioglu, A. (2017) Formation and distribution of $\mathrm{ZnO}$ nanoparticles and its effect on $\mathrm{E}$. coli in the presence of sepiolite and silica within the chitosan matrix via sonochemistry. Ultrason. Sonochem. 38, 720-725. https://doi. org/10.1016/j.ultsonch.2016.08.027.

56. Karakuş, S. (2019) Preparation and rheological characterization of Chitosan-Gelatine@ZnO-Si nanoparticles. Int. J. Biol. Macromol. 137, 821-828. https://doi.org/10.1016/j. ijbiomac.2019.06.231.

57. Karakus, S.; Ilgar, M.; Kahyaoglu, I.M.; Kilislioglu, A. (2019) Influence of ultrasound irradiation on the intrinsic viscosity of guar gum-PEG/rosin glycerol ester nanoparticles. Int. J. Biol. Macromol. 141, 1118-1127. https://doi. org/10.1016/j.ijbiomac.2019.08.254.

58. Nagvenkar, A.P.; Deokar, A.; Perelshtein, I.; Gedanken, A. (2016) A one-step sonochemical synthesis of stable $\mathrm{ZnO}$ PVA nanocolloid as a potential biocidal agent. J. Mater. Chem. B. 4, 2124-2132. https://doi.org/10.1039/c6tb00033a.

59. Wu, Y.D.; Wang, L.S.; Xiao, M.W.; Huang, X.J. (2008) A novel sonochemical synthesis and nanostructured assembly of polyvinylpyrrolidone-capped CdS colloidal nanoparticles. J. Non. Cryst. Solids. 354, 2993-3000. https://doi. org/10.1016/j.jnoncrysol.2007.12.005.

60. Theerdhala, S.; Bahadur, D.; Vitta, S.; Perkas, N.; Zhong, Z.; Gedanken, A. (2010) Sonochemical stabilization of ultrafine colloidal biocompatible magnetite nanoparticles using amino acid, L-arginine, for possible bio applications. Ultrason. Sonochem. 17, 730-737. https://doi.org/10.1016/j. ultsonch.2009.12.007.

61. Darroudi, M.; Zak, A.K.; Muhamad, M.R.; Huang, N.M.; Hakimi, M. (2012) Green synthesis of colloidal silver nanoparticles by sonochemical method. Mater. Lett. 66, 117-120. https://doi.org/10.1016/j. matlet.2011.08.016.

62. Nagvenkar, A.P.; Perelshtein, I.; Piunno, Y.; Mantecca, P.; Gedanken, A. (2019) Sonochemical one-step synthesis of polymer-capped metal oxide nanocolloids: antibacterial activity and cytotoxicity. ACS Omega. 4, 13631-13639. https://doi.org/10.1021/acsomega.9b00181. 
63. TSE (2010) TS EN 12390-6 - Testing hardened concrete Part 6: Tensile splitting strength for test specimens, Ankara.

64. ASTM (2013) C1437 - Standard test method for flow of hydraulic cement mortar. https://doi.org/10.1520/C1437-15.

65. TSE (2010) TS EN 12390-7 - Testing hardened concrete Part 7: Density of hardened concrete, Ankara.

66. TSE (2009) TS EN 196-1 - Methods of testing cement Part 1: Determination of strength Ankara.

67. Tonelli, F.; Masuelli, M.A. (2019) Acacia caven gum studies of hydrodynamic parameters. Evolut. Polym. Technol. J. Res. Art. 2, 1-11.

68. Cherif, E. (2019) A new correlation of viscosity and conductivity for the polyelectrolyte solutions of poly(sodium styrene sulphonate) (PSSNa) in N,N-dimethylformamide + water. Phys. Chem. Liq. https://doi.org/10.1080/00319104.2 019.1706177.

69. Boulet, M.; Britten, M.; Lamarche, F. (1998) Voluminosity of some food proteins in aqueous dispersions at various $\mathrm{pH}$ and ionic strengths. Food Hydrocoll. 12 [4], 433-441. https://doi.org/10.1016/S0268-005X(98)00009-5.

70. Joseph, R.; Devi, S.; Rakshit, A.K. (1991) Viscosity behaviour of acrylonitrile-acrylate copolymer solutions in dimethyl formamide. Polym. Int. 26 [2], 89-92. https://doi. org/10.1002/pi.4990260206.

71. Khemthong, P.; Luadthong, C.; Nualpaeng, W.; Changsuwan, P.; Tongprem, P.; Viriya-Empikul, N.; Faungnawakij, K. (2012) Industrial eggshell wastes as the heterogeneous catalysts for microwave-assisted biodiesel production. Catal. Today. 190, 112-116. https://doi. org/10.1016/j.cattod.2011.12.024.

72. Vichaphund, S.; Kitiwan, M.; Atong, D.; Thavorniti, P. (2011) Microwave synthesis of wollastonite powder from eggshells. J. Eur. Ceram. Soc. 31, 2435-2440. https://doi. org/10.1016/j.jeurceramsoc.2011.02.026.

73. Polat, S.; Sayan, P. (2020) Ultrasonic-assisted eggshell extract-mediated polymorphic transformation of calcium carbonate. Ultrason. Sonochem. 66, 105093. https://doi. org/10.1016/j.ultsonch.2020.105093.

74. Hassan, T.A.; Rangari, V.K.; Rana, R.K.; Jeelani, S. (2013) Sonochemical effect on size reduction of $\mathrm{CaCO}_{3}$ nanoparticles derived from waste eggshells. Ultrason. Sonochem. 20, 1308-1315. https://doi.org/10.1016/j. ultsonch.2013.01.016.

75. Tizo, M.S.; Blanco, L.A.V.; Cagas, A.C.Q.; Dela Cruz, B.R.B.; Encoy, J.C.; Gunting, J. V.; Arazo, R.O.; Mabayo, V.I.F. (2018) Efficiency of calcium carbonate from eggshells as an adsorbent for cadmium removal in aqueous solution. Sustain. Environ. Res. 28, 326-332. https://doi. org/10.1016/j.serj.2018.09.002.

76. Choudhary, R.; Koppala, S.; Swamiappan, S. (2015) Bioactivity studies of calcium magnesium silicate prepared from eggshell waste by sol-gel combustion synthesis. $J$. Asian Ceram. Soc. 3, 173-177. https://doi.org/10.1016/j. jascer.2015.01.002.

77. Jachimska, B.; Adamczyk, Z. (2007) Characterization of rheological properties of colloidal zirconia. J. Eur. Ceram. Soc. 27, 2209-2215. https://doi.org/10.1016/j. jeurceramsoc.2006.07.013.
78. Di Giuseppe, E.; Davaille, A.; Mittelstaedt, E.; François, M. (2012) Rheological and mechanical properties of silica colloids: from Newtonian liquid to brittle behaviour. Rheol. Acta. 51, 451-465. https://doi.org/10.1007/ s00397-011-0611-9.

79. van der Werff, J.C.; de Kruif, C.G. (1989) Hard-sphere colloidal dispersions: the scaling of rheological properties with particle size, volume fraction, and shear rate. J. Rheol. 33, 421-454. https://doi.org/10.1122/1.550062.

80. Çiftçi, D.; Kahyaoglu,T.; Kapucu, S.; Kaya, S. (2008) Colloidal stability and rheological properties of sesame paste. J. Food Eng. 87, 428-435. https://doi.org/10.1016/j. jfoodeng.2007.12.026.

81. Karakus, S.; Ilgar, M.; Tan, E.; Müge Sahin, Y.; Tasaltin, N.; Kilislioglu, A. (2020) The viscosity behaviour of PEGylated locust bean gum/rosin ester polymeric nanoparticles. Colloid Sci. Pharmac. Nanotech. IntechOpen. https:// doi.org/10.5772/intechopen.90248.

82. Asadi, A.; Pourfattah, F.; Miklós Szilágyi, I.; Afrand, M.; Żyła, G.; Seon Ahn, H.; Wongwises, S.; Minh Nguyen, H.; Arabkoohsar, A.; Mahian, O. (2019) Effect of sonication characteristics on stability, thermophysical properties, and heat transfer of nanofluids: A comprehensive review. Ultrason. Sonochem. 58, 104701. https://doi.org/10.1016/j. ultsonch.2019.104701.

83. Shadlou, S.; Wegner, L.D. (2016) Atomistic investigation of the effect of nano-structural shape on the mechanical response of $\mathrm{SiC} / \mathrm{Cu}$ interpenetrating phase nanocomposites. Comput. Mater. Sci. 117, 428-436. https://doi. org/10.1016/j.commatsci.2016.02.023.

84. Arno, M.C.; Inam, M.; Weems, A.C.; Li, Z.; Binch, A.L.A.; Platt, C.I.; Richardson, S.M.; Hoyland, J.A., Dove, A.P.; O'Reilly, R.K. (2020) Exploiting the role of nanoparticle shape in enhancing hydrogel adhesive and mechanical properties. Nat. Commun. 11, 1420. https://doi.org/10.1038/ s41467-020-15206-y.

85. Amani, M.; Khorasani, M.H.M.; Ghamary, M.H. (2016) Effect of salinity on the viscosity of water based drilling fluids at elevated pressures and temperatures. Hamad bin Khalifa Univ. Press. 2016, EEPP2318. https://doi. org/10.5339/qfarc.2016.eepp2318.

86. Allahverdi, A.; Kianpur K.; Moghbeli, M.R. (2010) Effect of polyvinyl alcohol on flexural strength and some important physical properties of Portland cement paste. Iran. J. Mater. Sci. Eng. 7 [1], 1-6.

87. Kim, J.-H.; Robertson, R.E. (1998) Effects of polyvinyl alcohol on aggregate-paste bond strength and the interfacial transition zone. Adv. Cem. Based Mater. 8 [2], 66-76. https://doi.org/10.1016/S1065-7355(98) 00009-1.

88. Knapen, E.; Van Gemert, D. (2006) Water-soluble polymers for modification of cement mortars. Int. Symp. Polym. Concr. Guimarães, Portugal, 85-93.

89. Gong, K.; Pan, Z.; Korayem, A. H.; Qiu, L.; Li, D.; Collins, F.; Wang, C. M.; Duan, W. H. (2015). Reinforcing effects of graphene oxide on Portland cement paste. J. Mater. Civil Engineer. 27 [2], 1-6. https://doi.org/10.1061/(ASCE) MT.1943-5533.0001125. 